News and Views

\title{
Urgent need for individual mobile phone and institutional reporting of at home, hospitalized, and intensive care unit cases of SARS-CoV-2 (COVID-19) infection
}

Peter A. McCullough ${ }^{1,2,3 *}$, John Eidt ${ }^{1,2,3}$, Janani Rangaswami ${ }^{4}$, Edgar Lerma ${ }^{5}$, James Tumlin ${ }^{6}$, Kevin Wheelan ${ }^{1,2,3}, \mathrm{Nevin} \mathrm{Katz}^{7}$, Norman E. Lepor ${ }^{8}$, Kris Vijay ${ }^{9}$, Sandeep Soman ${ }^{10}$, Bhupinder Singh ${ }^{11}$, Sean P. McCullough ${ }^{12}$, Haley B. McCullough ${ }^{13}$, Alberto Palazzuoli $^{14}$, Gaetano M. Ruocco ${ }^{14}$ and Claudio Ronco ${ }^{15,16}$

\author{
${ }^{1}$ Baylor University Medical Center, Dallas, TX 75226, USA \\ ${ }^{2}$ Baylor Heart and Vascular Institute, Dallas, TX 75226, USA \\ ${ }^{3}$ Baylor Jack and Jane Hamilton Heart and Vascular Hospital, Dallas, TX 75226, USA \\ ${ }^{4}$ Thomas Jefferson College of Medicine, Einstein Medical Center, Philadelphia, PA 19141, USA \\ ${ }^{5}$ University of Illinois at Chicago, Advocate Christ Medical Center Oak Lawn, IL 60453, USA \\ ${ }^{6}$ Emory University School of Medicine, Atlanta, GA 30322, USA \\ ${ }^{7}$ Johns Hopkins School of Medicine, Baltimore, MD 21205, USA \\ ${ }^{8}$ Cedars Sinai Medical Center, Los Angeles, CA 90048, USA \\ ${ }^{9}$ Abrazo Arizona Heart Hospital and Heart Institute in Phoenix, AZ 850169, USA \\ ${ }^{10}$ Henry Ford Hospital Detroit, MI 48202, USA \\ ${ }^{11}$ Cardiorenal Society of America, Phoenix, AZ 85004, USA \\ ${ }^{12}$ University of Texas McGovern Medical School, Houston, TX 77030, USA \\ ${ }^{13}$ University of Denver Sturm School of Law, Denver, CO 80210 , USA \\ ${ }^{14}$ University of Siena, Le Scotte Hospital Viale Bracci Siena Italy, Siena, SI 53100, Italy \\ ${ }^{15}$ University of Padova, Padova, PD 35122, Italy \\ ${ }^{16}$ University of Padova, Padova, International Renal Research Institute Vicenza, San Bortolo Hospital, Vicenza, VI 36100, \\ Italy \\ ${ }^{*}$ Correspondence: peteramccullough@gmail.com (Peter A. McCullough)
}

DOI: $10.31083 /$ i.rcm.2020.01.42

This is an open access article under the CC BY 4.0 license (https://creativecommons.org/licenses/by/4.0/).

Approximately 90 days of the SARS-CoV-2 (COVID-19) spreading originally from Wuhan, China, and across the globe has led to a widespread chain of events with imminent threats to the fragile relationship between community health and economic health. Despite near hourly reporting on this crisis, there has been no regular, updated, or accurate reporting of hospitalizations for COVID-19. It is known that many test-positive individuals may not develop symptoms or have a mild self-limited viral syndrome consisting of fever, malaise, dry cough, and constitutional symptoms. However some individuals develop a more fulminant syndrome including viral pneumonia, respiratory failure requiring oxygen, acute respiratory distress syndrome requiring mechanical ventilation, and in substantial fractions leading to death attributable to COVID-19. The pandemic is evolving in a clustered, non-inform fashion resulting in many hospitals with preparedness but few or no cases, and others that are completely overwhelmed.
Thus, a considerable risk of spread when personal protection equipment becomes exhausted and a large fraction of mortality in those not offered mechanical ventilation are both attributable to a crisis due to maldistribution of resources. The pandemic is amenable to self-reporting through a mobile phone application that could obtain critical information on suspected cases and report on the results of self testing and actions taken. The only method to understand the clustering and the immediate hospital resource needs is mandatory, uniform, daily reporting of hospital censuses of COVID-19 cases admitted to hospital wards and intensive care units. Current reports of hospitalizations are delayed, uncertain, and wholly inadequate. This paper urges all the relevant stakeholders to take up self-reporting and reporting of hospitalizations of COVID19 as an urgent task in combating this devastating pandemic.

\section{Keywords}


SARS-CoV-2; COVID-19; hospitalization; critical care; mortality; epidemiology; reporting; public health; resource utilization

The pandemic of SARS-CoV-2 (COVID-19), is rapidly expanding across Asia, Europe, the Middle East, North America Latin America, Australasia, and Africa expected to follow (Phelan , 2020). By March 16, 2020, the number of cases of COVID19 outside China had increased drastically with over 140 affected countries, states, or territories reporting infections to the World Health Organization (WHO). Based upon "alarming levels of spread and severity", and by the alarming levels of inaction", on March 11, 2020, the Director-General of WHO characterized the COVID-19 situation as a pandemic (World Health Organization , 2020a).

The WHO Strategic and Technical Advisory Group for Infectious Hazards (STAG-IH) regularly assesses COVID-19 and makes recommendations to WHO. STAG-IH's most recent formal meeting on March 12, 2020, included an update of the global COVID19 situation and an overview of the research priorities established by the WHO Research and Development Blueprint Scientific Advisory Group that met on March 2, 2020, in Geneva, Switzerland, to prioritize the recommendations of an earlier meeting on COVID-19 research held in early February, 2020 (World Health Organization , 2020b). In this blueprint, the authors stated: 'Delays in case detection and hospitalization can increase the risk of disease spread and raise the doubling time of the epidemic. Therefore, there is a need for further research to more accurately characterize estimates of the epidemiological parameters underlying the transmission dynamics of COVID-19 and identify effective control and mitigation measures." However, there was no call for reporting hospitalizations as critical events and metrics of the pandemic's irregular spread across the globe.

To respond to COVID-19, many countries are using a combination of containment and mitigation activities with the goal of attenuating community spread. Assessments that many times include estimated numbers of patients who have tested positive and may be sheltering at home or could be in-hospital (Adhikari et al., 2020). The problem with this form of reporting is that many have a self-limited illness and do not require utilization of healthcare resources while others require full intensive care unit support with all of its costs and intendent consequences and risk to the hospital workforce. On the other end of the spectrum, most sources of reporting include deaths attributable to COVID-19. The shortcoming of this form of reporting is that it is too late for a response to the next wave of individuals at risk. In addition, the deaths may not represent demand for health care resources. For example, the first death in Texas was a man who was in a nursing home and had influenza-like symptoms and was found dead. He was tested for COVID-19 at the end of life and was found to be positive postmortem.

Most national response strategies include varying levels of social distancing, sheltering in place, restricted access to hospitals and skilled nursing facilities, use of hand sanitizer, risk screening, self-quarantine, respiratory masks for those who are ill, selfdirected testing, and finally hospital evaluation and admission in isolated rooms for patients with symptomatic disease largely requiring supplemental oxygen or mechanical ventilation as a prin- cipal means of supportive care. None of the reporting systems to date leverage individuals in the population or hospitals as the principal source of information feeding into national centers such as Johns Hopkins University School of Public Health, the Centers for Disease Control, or the World Health Organization.(Centers for Disease Control and Prevention , 2020) The laboratory systems and community departments of health probably do not have the scale in terms of information technology or staff to do such large scale reporting. Thus the current results available to the public may be a gross under-reporting of the current epidemic and do not allow for the strategies and scale of resource re-allocation needed to provide supportive care to those becoming critically ill.

Preparation of hospitals and health systems has been largely applied anticipating a uniform surge of patients requiring either isolated medical ward rooms or intensive care and mechanical ventilation. This this form of readiness planning is not responsive to the clustering of cases that has been observed across the globe. The COVID-19 outbreaks have occurred in hotspots signaling an opportunity to move or shift resources from centers with little or no exposure to those who are at risk for or indeed are becoming overwhelmed with COVID-19 patients. Only a fundamental shift in case reporting can change these dynamics of the COVID-19 pandemic.

STAG-IH has made the following recommendations: 1) countries need to rapidly and robustly increase their preparedness, readiness, and response actions based on their national risk assessment, and 2) four WHO transmission scenarios are suggested to be considered: countries with no cases, first cases, first clusters, and community transmission and spread. STAG-IH suggests the common principles in use today to contain the spread of the virus. However, STAG-IH has made no recommendations on developing innovative methods of reporting and surveillance nor strategies that capitalize on redeployment of needed equipment or personal based upon the case-clustering epidemiology of COVID-19. If the cases are clustering at focal points, then there must be large regions and many centers that have undergone unnecessary preparedness and have not organized their capabilities to share resources to centers in greater need.

This paper focuses on two scalable and readily available methods of mass reporting of COVID-19 cases in real time to fill in important gaps in the operational reporting of this pandemic.

Proposal \#1: A mobile phone application that is freely downloadable and operationalized for one user and allowing for geographic tracking and self reporting of an illness consistent with COVID-19, disclosure of positive/negative testing if performed, and actions taken including self-quarantine, emergency department or clinic visit, or hospitalization. Additionally, such an app will allow reporting of recovery in nonfatal cases. Such an application would complement institutional reporting (Table 1) and allow further crowd-sourcing population-based principles to realize their potential in modern outbreak epidemiology. There are approximately 18 current mobile phone applications that deal with COVID-19 in one way or another however none are designed to allow for unique users to self-report their status and allow tracking or initial site of infection. A single social media website with sufficient data infrastructure could also accomplish what this proposal is calling for and could be secured with a PIN or other method of 
accounting for a single person reporting from a single location ${ }^{1}$.

Proposal \#2: Effective immediately and under government order if necessary, each and every hospital in the world should have a protocol to report each and every case of confirmed COVID-19 to a reporting agency that services that part of the world in which the hospital is situated. In the United Kingdom for example, that service may be the National Health Service or a designated data center. In many parts of the world the data center may be the World Health Organization. In the United States, either the Centers for Disease Control or the Johns Hopkins School of Public health (Fig. 2) may be immediate and appropriate reporting agencies. This means that some form of verbal or electronic case report will need to be completed with some key basic information to aid in the objectives beyond reporting the incidence and prevalence of COVID-19 cases. One innovative approach available now is Worldometer (Fig. 3) which is run by an international team with the goal of making world statistics available including the Coronavirus pandemic by integrating all of the public reporting systems mentioned in this paper as well as press reports and new notifications of outbreaks. This system appears to be dynamic and more nimble than any of the organizations managing data flow. The validity of the absolute numbers is not certain by our view, however, the British Broadcast Corporation has been listed as an endorsement on the Worldometer website.

Proposal \#3: For the United States, as a matter of routine national updates, the CDC, Department of Health and Human Services, US Surgeon General's Office, and the President Task Force for Corona should integrate sources of information and include a daily if not hourly reporting of cases stratified to indicate levels of infection:

1) Asymptomatic nasal specimen positive patients at home

2) Mild symptomatic positive patients at home

3) Patients hospitalized to medical wards

3) ICU and ventilator dependent illness

4) Death

Actions that could be taken with such reporting of information on a relatively immediate basis:

i. Identification of hotspots of suspected new epidemic clusters by patterns of self-reported illness and perceived exposure

ii. Capture and utilization of "drive-by" community testing that is done on an individual basis

iii. Hospital resource re-allocation. This pandemic is severely overwhelming some centers and not impacting others at all. This has two important implications. Unaffected or minimally impacted centers may be able to pick the load of elective surgeries and procedures. Additionally such centers could participate in resource allocation within their own systems and then on an inter-system or inter-hospital level. This is particularly important for the sharing of critical PPE and mechanical ventilators. Over time there may be a need and opportunity to share critical human resources such as nursing, physician, and technical staff. iv. Risk stratification by uniform capture key baseline variables, age, gender, race, occupation (direct healthcare worker/other) cardiovascular disease (especially heart failure), kidney disease (eGFR, on dialysis), diabetes mellitus, chronic lung disease, smoking history quantified in pack-years and current, dementia, baseline use of angiotensin converting enzyme inhibitors/angiotensin receptor II antagonists, and other illnesses

In summary, we see a grave need for the immediate development and reporting of self-illness, testing, and actions taken by individuals through a mobile phone application that is freely downloadable and allows for geographic monitoring with consent and assurances on anonymity and confidentiality. Secondly, we call for immediate and mandatory daily hospital census reporting of hospitalized and critical ill COVID-19 patients. Hourly reporting of test positive cases and deaths in the popular media is simply not enough and potentially misleading. Neither statistic is actionable and is leading to mass panic without organized solutions concerning redeployment of physical and human resources where they are needed most.

\section{Acknowledgments}

Thank numerous individuals participated in this study

\section{Conflict of Interest}

The authors declare no conflicts of interest statement.

Submitted: March 23, 2020

Accepted: March 24, 2020

Published: March 30, 2020

\section{References}

Adhikari, S. P., Meng, S., Wu, Y.-J., Mao, Y.-P., Ye, R.-X., Wang, Q.-Z., Sun, C., Sylvia, S., Rozelle, S., Raat, H. and Zhou, H. (2020) Epidemiology, causes, clinical manifestation and diagnosis, prevention and control of coronavirus disease (COVID-19) during the early outbreak period: a scoping review. Infectious Diseases of Poverty 9, 29.

CDC. (2020) Severe Outcomes Among Patients with Coronavirus Disease 2019 (COVID-19) — United States, February 12-March 16, 2020. MMWR: Morbidity and Mortality Weekly Report 69, 343-346. DOI: http://dx.doi.org/10.15585/mmwr.mm6912e2

Phelan, A. L., Katz, R. and Gostin, L. O. (2020) The Novel Coronavirus Originating in Wuhan, China: Challenges for Global Health Governance. JAMA323, 709-710.

World Health Organization (2020) Coronavirus disease (COVID2019): situation reports: 55. March 15, 2020. Available at: https://www.who.int/docs/default-source/coronaviruse/situation-rep orts/20200315-sitrep-55-covid-19.pdf?sfvrsn=33daa5cb_6 (accessed March 16, 2020).

World Health Organization (2020) WHO Virtual press conference on COVID-19. March 11, 2020. Available at: https://www.who.int/docs/default-source/coronaviruse/transcripts /who-audio-emergencies-coronavirus-press-conference-full-and-fin al-11mar2020.pdf?sfvrsn=cb432bb3_2 (accessed March 16, 2020).

\footnotetext{
1 https://scholar.google.com/scholar?as_ylo=2016\&q=social+medi $\mathrm{a}+$ prediction + of + influenza + epidemic\&hl $=$ en\&as_sdt $=0,23$
} 


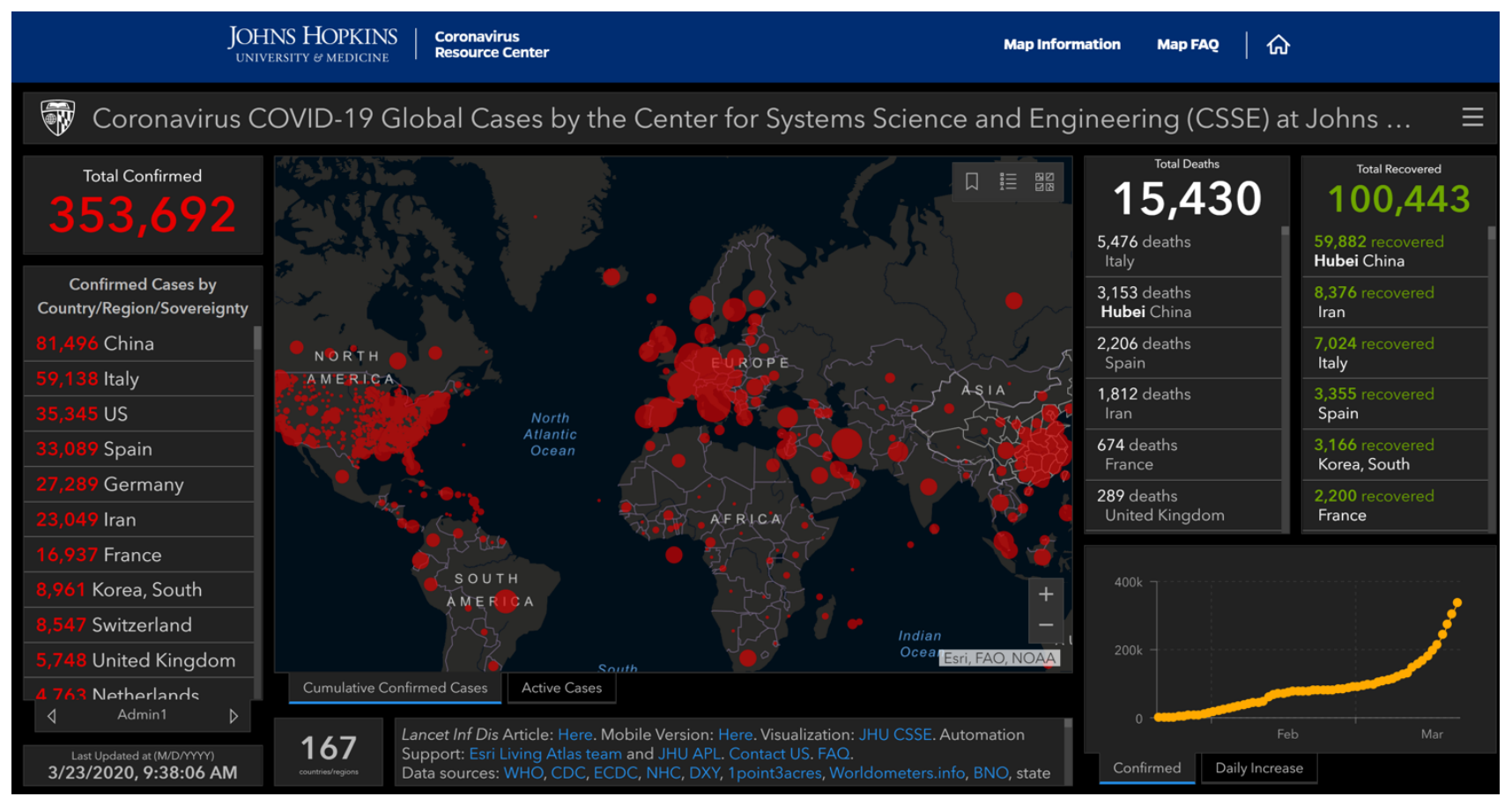

Figure 1. Sample report access from the Johns Hopkins website on March 23, 2020

FIGURE 2. Coronavirus disease 2019 (COVID-19) hospitalizations, ${ }^{*}$ intensive care unit (ICU) admissions, ${ }^{\dagger}$ and deaths, ${ }^{\S}$ by age group - United States, February 12- March 16, 2020

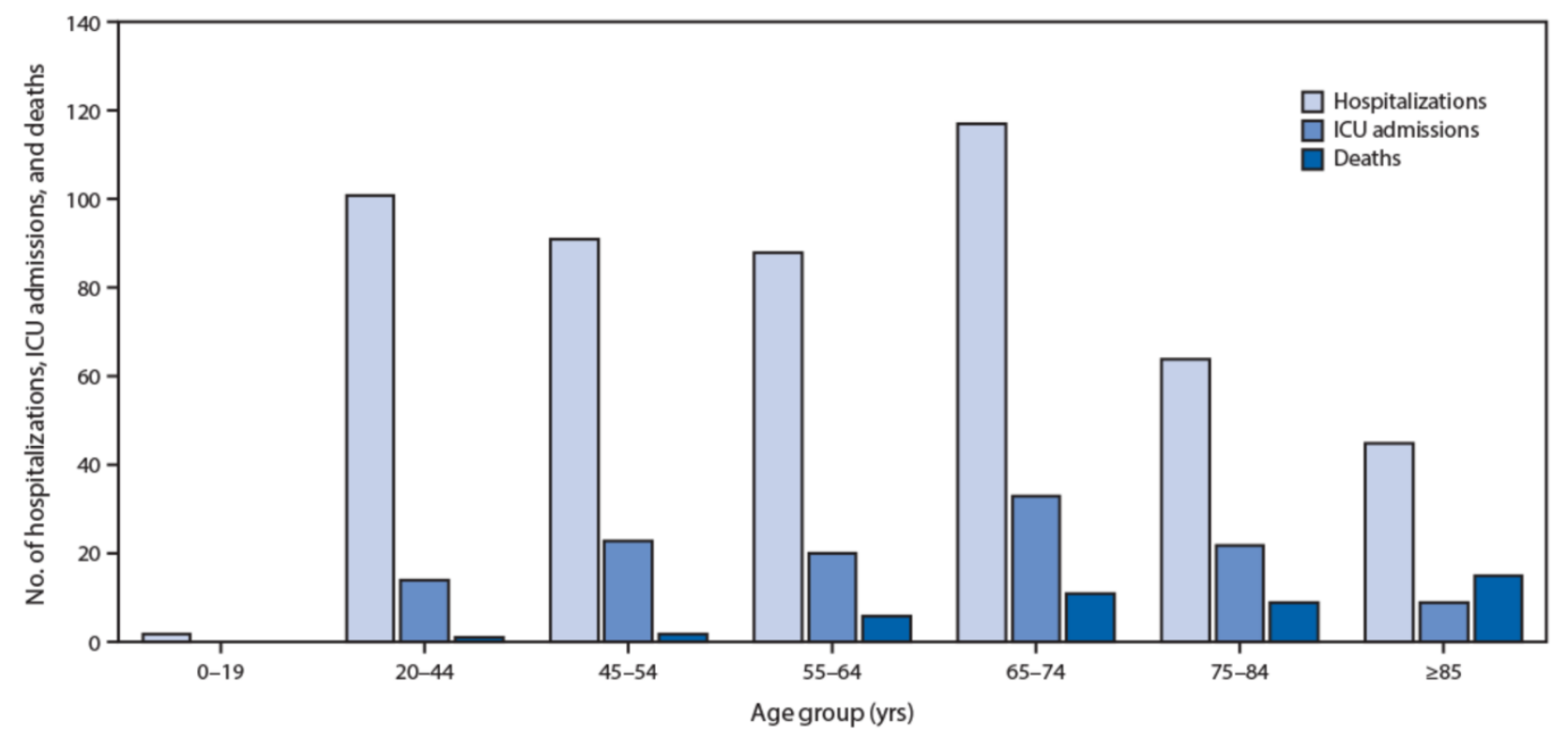

* Hospitalization status missing or unknown for 1,514 cases.

${ }^{+}$ICU status missing or unknown for 2,253 cases.

$\S$ Illness outcome or death missing or unknown for 2,001 cases.

Figure 2. Sample report of hospitalized cases from the CDC website on March 22, 2020, data unchanged since March 16, 2020 


\begin{tabular}{|c|c|c|c|c|c|c|c|c|}
\hline $\begin{array}{l}\text { Country, } \\
\text { Other }\end{array}$ & $\begin{array}{l}\text { Total } \\
\text { Cases } \downarrow\end{array}$ & $\begin{array}{l}\text { New } \\
\text { Cases } \downarrow \uparrow\end{array}$ & $\begin{array}{l}\text { Total } \\
\text { Deaths } \downarrow \uparrow\end{array}$ & $\begin{array}{l}\text { New } \\
\text { Deaths } \downarrow \uparrow\end{array}$ & $\begin{array}{l}\text { Total } \\
\text { Recovered } \downarrow \uparrow\end{array}$ & $\begin{array}{l}\text { Active } \\
\text { Cases } \downarrow \uparrow\end{array}$ & $\begin{array}{l}\text { Serious, } \\
\text { Critical } \downarrow \uparrow\end{array}$ & $\begin{array}{l}\text { Tot Cases/ } \\
1 \mathrm{M} \text { pop }\end{array}$ \\
\hline China & 81,093 & +39 & 3,270 & +9 & 72,703 & 5,120 & 1,749 & 56 \\
\hline Italy. & 59,138 & & 5,476 & & 7,024 & 46,638 & 3,000 & 978 \\
\hline$\underline{\text { USA }}$ & 39,389 & $+5,843$ & 467 & +48 & 187 & 38,735 & 1,040 & 119 \\
\hline Spain & 33,089 & $+4,321$ & 2,206 & +434 & 3,355 & 27,528 & 2,355 & 708 \\
\hline Germany. & 27,546 & $+2,673$ & 115 & +21 & 422 & 27,009 & 23 & 329 \\
\hline$\underline{\text { Iran }}$ & 23,049 & $+1,411$ & 1,812 & +127 & 8,376 & 12,861 & & 274 \\
\hline France & 16,689 & +671 & 674 & & 2,200 & 13,815 & 1,746 & 256 \\
\hline S. Korea & 8,961 & +64 & 111 & +7 & 3,166 & 5,684 & 59 & 175 \\
\hline Switzerland & 8,547 & $+1,073$ & 118 & +20 & 131 & 8,298 & 141 & 988 \\
\hline$\underline{\text { UK }}$ & 5,837 & +154 & 289 & +8 & 135 & 5,413 & 20 & 86 \\
\hline Netherlands & 4,749 & +545 & 213 & +34 & 2 & 4,534 & 435 & 277 \\
\hline Austria & 4,075 & +493 & 21 & +5 & 9 & 4,045 & 14 & 452 \\
\hline Belgium & 3,743 & +342 & 88 & +13 & 401 & 3,254 & 322 & 323 \\
\hline Norway. & 2,547 & +162 & 10 & +3 & 6 & 2,531 & 41 & 470 \\
\hline Portugal & 2,060 & +460 & 23 & +9 & 14 & 2,023 & 47 & 202 \\
\hline Sweden & 2,046 & +112 & 25 & +4 & 16 & 2,005 & 104 & 203 \\
\hline Australia & 1,717 & +108 & 7 & & 88 & 1,622 & 11 & 67 \\
\hline Brazil & 1.620 & +74 & 25 & & 2 & 1.593 & 18 & 8 \\
\hline
\end{tabular}

Figure 3. Sample report of all information reported on Worldmeter accessed March 23, 2020 
Table 1. Various internet reporting of the COVID-19 pandemic. These sources are commonly taken and redisplayed in the television and other news media.

\begin{tabular}{|c|c|c|c|c|}
\hline Source & Web Site URLs & Information Reported & Sources of Information & Information not Reported \\
\hline $\begin{array}{c}\text { Centers for } \\
\text { Disease Control } \\
\text { and Prevention }\end{array}$ & $\begin{array}{l}\text { https://www.cdc.gov/mmwr/volumes/69/wr/mm6912e2.htm\# } \\
\text { F2_down } \\
\text { https://www.cdc.gov/coronavirus/2019-ncov/cases-updates/c } \\
\text { ases-in-us.html }\end{array}$ & $\begin{array}{l}\text { 1.Total cases } \\
\text { 2.Total deaths } \\
\text { 3.Hospitalizations } \\
\text { 4. ICU admissions }\end{array}$ & 10 different sources ${ }^{a}$ & 1.Self-reported cases \\
\hline $\begin{array}{l}\text { Johns Hopkins } \\
\text { University } \\
\text { \& Medicine }\end{array}$ & https://coronavirus.jhu.edu/map.html & $\begin{array}{l}\text { 1.Total cases } \\
\text { 2.Total deaths } \\
\text { 3.Total recovered }\end{array}$ & $\begin{array}{l}\text { 1.DXY (online platform run by members of the Chinese medical community); } \\
\text { 2.China CDC (CCDC), } \\
\text { 3.Hong Kong Department of Health, } \\
\text { 4.Macau Government, } \\
\text { 5.Taiwan CDC, } \\
\text { 6.European CDC (ECDC) } \\
\text { 7.World Health Organization (WHO) } \\
\text { 8.US CDC } \\
\text { 9. Government of Canada } \\
\text { 10.Australia Government Department of Health } \\
\text { 11.Various state or territory health authorities }\end{array}$ & $\begin{array}{l}\text { 1.Self-reported cases } \\
\text { 2.Hospitalizations } \\
\text { 3.ICU admissions }\end{array}$ \\
\hline
\end{tabular}

1.Total cases

2.Total deaths

3.Total recovered

4.Infected patients in mild

1.Self-reported cases

https://www.worldometers.info/coronavirus/country/us/

condition; serious/critical condition

2.Hospitalizations

Worldometer $^{b}$

5.Total Recovered

\begin{tabular}{ll}
\hline World Health & https://www.who.int/emergencies/diseases/novel-coronavirus \\
-2019 &
\end{tabular}

Organization

https://www.who.int/docs/default-source/coronaviruse/situa

1.Total cases

2.Total deaths

3.ICU admissions

on-reports/20200322-sitrep-62-covid-19 pdf?sfvrsn=f7764c

1.Self-reported cases

2.Hospitalizations

3.ICU admissions 
${ }^{a}$ World Health Organization. Coronavirus disease 2019 (COVID-19) situation report-57. Geneva, Switzerland: World Health Organization; 2020. https://www.who.int/docs/default-source/corona viruse/situation-reports/20200317-sitrep-57-covid-19.pdf?sfvrsn=a26922f2_2pdficonexternalicon; World Health Organization. Coronavirus disease 2019 (COVID-19) situation report-51. Geneva, Switzerland: World Health Organization; 2020. https://www.who.int/docs/default-source/coronaviruse/situation-reports/20200311-sitrep-51-covid-19.pdf?sfvrsn=1ba62e57_10pdficonexternalic on; Novel Coronavirus Pneumonia Emergency Response Epidemiology Team. The epidemiological characteristics of an outbreak of 2019 novel coronavirus diseases (COVID-19) in China [Chinese]. Chinese Center for Disease Control and Prevention Weekly 2020;41:145-51. PubMedexternal icon; CDC. CDC, Washington State report first COVID-19 death [Media statement]. Atlanta, GA: US Department of Health and Human Services, CDC; 2020. https://www.cdc.gov/media/releases/2020/s0229-COVID-19-first-death.html; CDC. Coronavirus disease 2019 (COVID-19): cases in U.S. Atlanta, GA: US Department of Health and Human Services, CDC; 2020. https://www.cdc.gov/coronavirus/2019-ncov/cases-in-us.html; CDC. Coronavirus disease 2019 (COVID-19): information for health departments on reporting a person under investigation (PUI), or presumptive positive and laboratory-confirmed cases of COVID-19. Atlanta, GA: US Department of Health and Human Services, CDC; 2020. https://www.cdc.gov/coronavirus/2019-ncov/php/reporting-pui.html; CDC. Coronavirus disease 2019 (COVID-19): if you are at higher risk. Get ready for COVID-19 now. Atlanta, GA:US Department of Health and Human Services; 2020. https://www.cdc.gov/coronavirus/2019-ncov/specific-groups/high-risk-complications.html; CDC. Coronavirus disease 2019 (COVID-19): schools, workplaces, \& community locations. Atlanta, GA: US Department of Health and Human Services, CDC; 2020. https://www.cdc.gov/coronavirus/2019-ncov/community/in dex.html?CDC_AA_refVal=https\%3A\%2F\%2Fwww.cdc.gov\%2Fcoronavirus\%2F2019-ncov\%2Fpreparing-individuals-communities.html; Administration for Community Living. 2017 profile of older Americans. Washington, DC: US Department of Health and Human Services, Administration for Community Living; 2018. https://acl.gov/sites/default/files/Aging\%20and\%20Disability\% 20in\%20America/2017OlderAmericansProfile.pdfpdfliconexternallicon; McMichael TM, Clark S, Pogosjans S, et al. COVID-19 in a long-term care facility—King County, Washington, February 27-March 9, 2020. MMWR. Morb Mortal Wkly Rep 2020. Epub March 18, 2020.

$b$ Worldometers.info; Publishing Date: 23 March, 2020; Place of publication: Dover, Delaware, U.S.A

${ }^{c}$ Novel Coronavirus (2019-nCoV) situation reports - World Health Organization (WHO); 2019 Novel Coronavirus (2019-nCoV) in the U.S. -. U.S. Centers for Disease Control and Prevention (CDC); Outbreak Notification - National Health Commission (NHC) of the People's Republic of China; Novel coronavirus (2019-nCoV) - Australian Government Department of Health; Novel coronavirus 2019-nCoV: early estimation of epidemiological parameters and epidemic prediction - Jonathan M. Read et al, Jan. 23,2020; Early Transmissibility Assessment of a Novel Coronavirus in Wuhan, China - Maimuna Majumder and Kenneth D. Mandl, Harvard University - Computational Health Informatics Program - Posted: 24 Jan 2020 Last revised: 27 Jan 2020 ; Report 3: Transmissibility of 2019-nCoV - 25 January 2020 - Imperial College London; Case fatality risk of influenza A(H1N1pdm09): a systematic review - Epidemiology. Nov. 24, 2013; A novel coronavirus outbreak of global health concern - Chen Wang et al. The Lancet. January 24, 2020; Symptoms of Novel Coronavirus (2019-nCoV) - CDC; China's National Health Commission news conference on coronavirus - Al Jazeera. January 26, 2020; Wuhan lockdown 'unprecedented', shows commitment to contain virus: WHO representative in China - Reuters. January 23, 2020; Statement on the meeting of the International Health Regulations (2005) Emergency Committee regarding the outbreak of novel coronavirus (2019-nCoV) - WHO, January 23, 2020; International Health Regulations Emergency Committee on novel coronavirus in China - WHO, January 30, 2020; Human-to-human transmission of Wuhan virus outside of China, confirmed in Germany, Japan and Vietnam - The Online Citizen, Jan. 29, 2020; Who: "Live from Geneva on the new \#coronavirus outbreak; CDC Confirms Person-to-Person Spread of New Coronavirus in the United States - CDC Press Release, Jan. 30, 2020; CMO confirms cases of coronavirus in England - CMO, UK, Jan. 31, 2020; Coronavirus in France: what you need to know - The Local France, Jan. 31, 2020; First two persons infected with coronavirus identified in Russia - Tass, Jan. 31, 2020; Updated understanding of the outbreak of 2019 novel coronavirus (2019nCoV) in Wuhan, China - Journal of Medical Virology, Jan. 29, 2020; Estimating the effective reproduction number of the 2019-nCoV in China - Zhidong Cao et al., Jan. 29, 2020; Preliminary estimation of the basic reproduction number of novel coronavirus (2019-nCoV) in China, from 2019 to 2020: A data-driven analysis in the early phase of the outbreak - Jan. 30, 2020; Coronavirus: Window of opportunity to act, World Health Organization says BBC, Feb, . 4, 2020; Clinical Characteristics of 138 Hospitalized Patients With 2019 Novel Coronavirus-Infected Pneumonia in Wuhan, China - Wang et. al, JAMA, Feb. 7, 2020. 